\title{
THE PERFORMANCE COMPARISON OF THIRD GENERATION (3G) TECHNOLOGIES FOR INTERNET SERVICES IN BANGKOK
}

\author{
Sanon Chimmanee \& Suttisak Jantavongso \\ Rangsit University, Thailand
}

sanon.s@rsu.ac.th; suttisak.j@rsu.ac.th

\begin{abstract}
Like other countries, users in Thailand demand to experience the highest possible level of quality of $3 \mathrm{G}$ services. In contrast, operators prefer to obtain maximum revenue. To facilitate these needs, this paper proposes two conceptual frameworks for (1) performance testing (QoS measurement) and (2) network optimization. The network optimization framework consists of KPI definition, network performance monitoring, parameter tuning, and optimized network processes; while the network performance monitoring process contains (1) traffic measurement (operator's side) and (2) QoS measurement (user's side). Operators need these information for the network performance monitoring to support the parameter tuning process and for user satisfactions. In this study, the latency tests, user data rates, and speed tests were the QoS measurements used to compare the performance of three Thai major $3 \mathrm{G}$ network operators; and $850 / 900 \mathrm{MHz}$ and $2100 \mathrm{MHz}$ bands in Bangkok. In terms of user satisfactions, the QoS measurements revealed that TrueMoveH offered the better performance in the user data rates; while AIS was the better in the latency tests. The speed tests were spitted between DTAC and TrueMoveH. Finally, the study identified that $3 \mathrm{G}$ services on $2100 \mathrm{MHz}$ performed better than $850 / 900 \mathrm{MHz}$.
\end{abstract}

Keywords: 3G, Network Optimization, Network Performance Monitoring, Parameter Tuning, QoS.

\section{INTRODUCTION}

For Thailand, the Third Generation (3G) technologies have broadband capabilities to offer Internet with multimedia services. Thus, $3 \mathrm{G}$ is envisioned as the potential solution for the Thailand's lagged behind others countries 
in the region. Thailand was one of the last few countries in Southeast Asia to introduce $3 \mathrm{G}$ services. The $3 \mathrm{G}$ on $2100 \mathrm{MHz}(2.1 \mathrm{GHz})$ spectrum auction concluded in 2012 was the first milestone towards transforming Thailand's mobile telecommunication industry (Malisuwan, Teppayayon, Madan, Sivaraks, \& Kaewphanuekrungsi, 2013). AIS, DTAC, and TrueMove are three major operators in Thailand. They have occupied Second Generation (2G) and $3 \mathrm{G}$ networks to serve both $3 \mathrm{G}$ capable and Global System for Mobile Communications (GSM) devices (NBTC, 2014).

While Thailand begins to deploy the Fourth Generation Long Term Evolution (4G LTE), it is important to study and understand the characteristics of the current $3 \mathrm{G}$ technologies to maximize the potential benefits. For Thailand, $3 \mathrm{G}$ networks will continue to be the dominant technologies for the foreseeable future with approximately 55 million $3 \mathrm{G}$ numbers (NBTC, 2014). 3G technologies offer Internet services with rapid data access to support the prolific growth of smartphones and tablets to Thai users. The usage of the Internet in Thailand through mobile devices has steadily increased due to the portability, on-the-move connectivity, and user convenient. According to the Electronic Transactions Development Agency or ETDA (2013), the hours that Thais spent on the Internet in 2013 was almost 100\% increased from 2001. This finding is in line with the National Broadcasting and Telecommunications Commission or NBTC (2013).

\section{PROBLEM STATEMENT}

The $3 \mathrm{G}$ industry is still growing, while Thailand is preparing for $4 \mathrm{G}$ networks. Rapid increase in the demand for data services has pushed operators to optimize their networks. At the same time, operators must ensure that satisfactory services are provided to the users. Users are expected to experience the highest possible level of service quality. Efficient resource allocation is a vital contributor to economic growth and success in telecommunications industry management of Thailand (Malisuwan, Kaewphanuekrungsi, Madan, $\&$ Sivaraks, 2015). Network resource become scarce due to the increase in demand for wireless services (Ramli et al., 2013).This in turn leads to network optimization which is the continuous process that keeps on increasing the quality of the network (Saxena \& Jadon, 2013). Furthermore, network quality can be viewed from two different perspectives, one is the user and other is the operator. While there is no single universal measure of performance for a telecommunications system (Sköld, Lundevall, Parkvall, \& Sundelin, 2005), an optimized network could improve perceived Quality of Service (QoS) and system performance. 
Traditionally, 3G services can be implemented of multiband antennas at $900 \mathrm{MHz}, 1800 \mathrm{MHz}$ and $2100 \mathrm{MHz}$ (Cela, Kamo, Cakaj, Muka, \& Mitrushi, 2013). Multiband operation offers significant gains by bandwidth extension. According to Lachowski, Maternia, \& Gorzynski (2011), operators may consider to reuse $900 \mathrm{MHz}$ (occupied by the GSM networks) to enhance experience of the growing number of $3 \mathrm{G}$ users. The usage of $900 \mathrm{MHz}$ expands bandwidth available for transmission. This brings significant gains in coverage in terms of the cell edge users, who often suffer from heavy interference conditions. Despite this, load imbalance often results in ineffective utilization of network resource. As a result, network bandwidths have become important and need to be efficiently assigned to potential and demanding operators. Thus, this paper also describes the effects of utilizing available bands other than $2100 \mathrm{MHz}$ in a multiband operation mode.

\section{RESEARCH OBJECTIVES}

Two objectives of the research are presented in this paper. The first (A), is the development of conceptual frameworks for (A1) performance testing and (A2) network optimization that would enable operators in Thailand to optimize their network performance. The second (B), is to evaluate the performance comparison of (B1) $3 \mathrm{G}$ operators and (B2) $3 \mathrm{G}$ services on $850 / 900 \mathrm{MHz}$ and 2100MHz bands in Thailand.

In relation to the first objective, namely the performance testing, it involves the QoS measurements of the services (1) by the 3G operators (Objectives B1) and (2) on $850 / 900 \mathrm{MHz}$ and $2100 \mathrm{MHz}$ bands (Objectives B2) respectively. The acquired knowledge from the QoS measurements are needed for the parameter tuning process. The details of parameter tuning process are described in a later section.

The paper makes both theoretical and practical contributions. In terms of theoretical contributions to the context of radio network planning and optimization, this paper contributes to enriching body of knowledge on radio network planning and optimization. It emphasizes especially on load sharing between bands. From a practical perspective, this paper provides some directions to Thai users about the performance of services provided by the operators. This would benefit users in Thailand in selecting their operators without a commercial bias intention. 


\section{RESEARCH CONTEXT}

\section{Evolution of 3G/4G Technologies}

Prior to $3 \mathrm{G}$ technologies, Internet services on mobile devices is possible via General Packet Radio Service (GPRS). GPRS (2.5G) enables packet-switched functionality to a GSM network (circuit-switched). According to the European Telecommunications Standards Institute or ETSI (2014b, "Overview", para. 2 ), it supports a download data rate of up to $171 \mathrm{kbps}$. The maximum data rates achievable would be between 15 and 40kbps. Enhanced Data GSM Evolution (EDGE) is a $2.75 \mathrm{G}$ network by ETSI (2014a, "Introduction", para. 2). While, EDGE has some characteristics of a $3 \mathrm{G}$ network, it does not fully satisfy the specification. The increase in data speeds to $384 \mathrm{kbps}$ placed EDGE as an early state of 3G (3GPP, 2014, "EDGE... almost 3G", para. 3). 3G network equipped with download speed of up to $3.1 \mathrm{Mbps}$ and was expected to deliver quality multimedia to mobile devices.

Although, there is no single official body that sets requirements for $2.5 \mathrm{G}, 3 \mathrm{G}$, 3.5G, or 4G technologies, the Universal Mobile Telecommunications Service (UMTS), 3G standards developed by the 3rd Generation Partnership Project (3GPP) is widely adopted (Kurose \& Ross, 2013). In 2002, 3GPP release 5 presented High Speed Downlink Packet Access (HSDPA), which is based on a $3 \mathrm{G}$ network and an enhancement to 3G. Download speed is up to 14Mbps, known as 3.5G. The first High Speed Packet Access (HSPA) specifications supported increased peak data rates of up to $14 \mathrm{Mbps}$ in the downlink (DL) and $5.76 \mathrm{Mbps}$ in the uplink (UL), which is a combination of HSDPA and High Speed Uplink Packet Access (HSUPA) that is 3GPP release 6 in 2005. In 2007, 3GPP release 7 presented High Speed Packet Access Plus (HSPA+), which provides an evolution of HSPA referred to as $3.75 \mathrm{G}$. It provides data rates up to $168 \mathrm{Mbps}$ in the DL and $22 \mathrm{Mbps}$ in the UL.

3GPP release 8 in 2008 and release 9 in 2010 introduce LTE referred to as $3.9 \mathrm{G}$, which provides for peak user data rates of up to $300 \mathrm{Mbps}$ in the DL, UL rates up to $75.4 \mathrm{Mbps}$, and latency as low as $10 \mathrm{~ms}$. It is named as a Pre $4 \mathrm{G}$ technology. However, it is commonly known as 4G LTE. The specified peak speed in the specifications for $4 \mathrm{G}$ services are 100Mbps for high mobility communication, and $1 \mathrm{Gbps}$ for low mobility communication. $4 \mathrm{G}$ with LTE-Advanced release 10 was designed to meet all International Mobile Telecommunications-Advanced (IMT-Advanced) requirements including data rates of up to $1 \mathrm{Gbps}$ in the DL and 500Mbps in the UL in 2011 (Abdullah, Abdullah, Yonis, \& Ghanim, 2011). Table 1 presents the evolution of 3 GPP specifications. 
Table 1

Evolution of 3GPP Specifications According to Nakamura (2011)

\begin{tabular}{|c|c|c|c|c|}
\hline \multirow{2}{*}{$\begin{array}{l}\text { Freeze } \\
\text { Date }\end{array}$} & \multirow{2}{*}{$\begin{array}{c}\text { 3GPP } \\
\text { Release }\end{array}$} & \multirow{2}{*}{ Technologies } & \multicolumn{2}{|c|}{ Peak Rates in Downlink } \\
\hline & & & HSPA Evolution & LTE Evolution \\
\hline $\begin{array}{l}\text { June } 2002- \\
\text { March } 2005\end{array}$ & Release 5-6 & $\begin{array}{c}\text { HSPA (HSDPA + } \\
\text { HSUPA) }\end{array}$ & $14 \mathrm{Mbps}$ & Not Applicable \\
\hline $\begin{array}{c}\text { December } \\
2007\end{array}$ & Release 7 & HSPA+ & $\begin{array}{c}21-28 \mathrm{Mbps} \\
\left(2 \times 2 \mathrm{MIMO}^{*}\right)\end{array}$ & Not Applicable \\
\hline $\begin{array}{c}\text { December } \\
2008\end{array}$ & Release 8 & LTE & $\begin{array}{c}\text { 42Mbps } \\
(2 \times 2 \mathrm{MIMO}), \\
\text { 10MHz Bandwidth }\end{array}$ & $\begin{array}{c}\text { 300Mbps }(4 \mathrm{x} 4 \\
\text { MIMO), } \\
20 \mathrm{MHz} \\
\text { Bandwidth }\end{array}$ \\
\hline $\begin{array}{c}\text { December } \\
2009\end{array}$ & Release 9 & & $\begin{array}{c}84 \mathrm{Mbps} \\
(2 \times 2 \mathrm{MIMO}), \\
10 \mathrm{MHz} \text { Bandwidth }\end{array}$ & \\
\hline \multirow[t]{2}{*}{ March 2011} & Release 10 & LTE-Advanced & $\begin{array}{c}168 \mathrm{Mbps} \\
(2 \times 2 \mathrm{MIMO}), \\
20 \mathrm{MHz} \text { Bandwidth }\end{array}$ & $\begin{array}{c}3 \mathrm{Gbps} \\
\text { (8x8 MIMO), } \\
100 \mathrm{MHz} \\
\text { Bandwidth }\end{array}$ \\
\hline & Release 11 & & $\begin{array}{c}\text { 366Mbps } \\
(2 \times 2 \mathrm{MIMO}), \\
40 \mathrm{MHz} \text { Bandwidth }\end{array}$ & \\
\hline
\end{tabular}

Note. *Multiple-Input and Multiple-Output

\section{QoS Requirements and Measurements of 3G/4G Networks}

Operators need to make business decisions related to the 'Quality of Service' (QoS). Planning networks, collecting information, processing of raw data, analyzing and distributing information, optimizing network capacity and quality, and measuring traffic are the tasks of network management. The term QoS has multiple meanings (Laiho, Wacker, \& Novosad, 2006). For example, requirements of user, planned by operator, delivered by operator, and perceived by user. QoS is related to acceptable delays and throughput as listed in Tables 1 and 2. Estimation of existing delays in the network planning phase requires good knowledge of user behavior and understanding of the functions of the packet scheduler.

However, QoS measurements for end-to-end service quality should be provided from the viewpoint of the users as well as the operators. Hence, it is the users who make a decision about the satisfaction of services (Laiho 
et al., 2006). There are many QoS measurement methods of the Internet services provided by network operators (Darst \& Ramanathan, 1999; Haryadi \& Andina, 2012; Hu, Liu, \& Tan, 2010). Examples of these are latency, user data rates, and speed test measurements.

Table 2

QoS Requirements (KPI) and Measurements in U-Plane Latency (RTT) for Ping Tests (32 bytes Payload Used)

\begin{tabular}{|c|c|c|}
\hline \multirow{2}{*}{ Technologies } & \multicolumn{2}{|c|}{ Round Trip Time (RTT) for U-Plane } \\
\hline & KPI & RTT Testing \\
\hline $3 \mathrm{G}$ & $\begin{array}{c}220 \mathrm{~ms} \\
(\text { Ranta, 2004) }\end{array}$ & $\begin{array}{c}348.02 \mathrm{~ms} \\
/ 362.37 \mathrm{~ms} \\
\text { (Chen, Towsley, Nahum, Gibbens, \& } \\
\text { Lim, 2012) }\end{array}$ \\
\hline $\begin{array}{l}\text { HSDPA / } \\
\text { Release'99 }\end{array}$ & $\begin{array}{c}90 \mathrm{~ms} \\
\text { (Tapia, Liu, Karimli, \& } \\
\text { Feuerstein, 2009) } \\
/ \text { 100ms } \\
\text { (Tarun, 2014) (Person, 2008) }\end{array}$ & - \\
\hline HSPA & $\begin{array}{c}50 \mathrm{~ms} \\
\text { (Person, 2008) } \\
/ 60 \mathrm{~ms} \\
\text { (Fricke et al., 2012) } \\
/ 70 \mathrm{~ms} \\
\text { (Tapia et al., 2009) }\end{array}$ & $\begin{array}{c}99 \mathrm{~ms} \\
\text { / 112ms } \\
\text { (Jørgensen, Rodriguez Larrad, Elling, } \\
\text { \& Mogensen, 2014) }\end{array}$ \\
\hline HSPA+ & $\begin{array}{c}40 \mathrm{~ms} \\
\text { (Fricke et al., 2012) } \\
\text { / 50ms } \\
\text { (Person, 2008) }\end{array}$ & $\begin{array}{c}115.32 \mathrm{~ms} \\
\text { (Chen et al., 2012) }\end{array}$ \\
\hline $\begin{array}{l}\text { HSPA Release } \\
8 / \\
\text { Release } 9 \\
10 \mathrm{MHz} \text { BW }\end{array}$ & $\begin{array}{c}25 \mathrm{~ms} \\
\text { (Real Wireless Ltd, 2012) }\end{array}$ & $\begin{array}{c}\text { 42ms } \\
\text { (Laner et al., 2012) } \\
\text { / 38ms } \\
\text { (Mohan, Kapoor, \& Mohanty, 2011) }\end{array}$ \\
\hline LTE & $\begin{array}{c}20 \mathrm{~ms} \\
\text { (Fricke et al., 2012) } \\
16 \mathrm{~ms} \\
\text { (Person, 2008) }\end{array}$ & $\begin{array}{c}36 \mathrm{~ms} \\
\text { (Laner et al., 2012) } \\
\text { / 32ms } \\
\text { (Mohan et al., 2011) } \\
/ 141.62 \mathrm{~ms} \\
/ 65.84 \mathrm{~ms} \\
/ 124.64 \mathrm{~ms} \\
77.31 \mathrm{~ms} \\
\text { (Chen et al., 2012) }\end{array}$ \\
\hline LTE-Advanced & $\begin{array}{c}10 \mathrm{~ms} \\
\text { (Vacirca, Ricciato, \& Pilz, 2005) }\end{array}$ & - \\
\hline
\end{tabular}

Haryadi and Andina (2012) studied the QoS measurement of File Transfer Protocol (FTP) services in 3G networks. Almutairi, Al-Jame, and A-Buraikan (2009) evaluated the QoS with Round Trip Time (RTT), FTP, and World Wide 
Web (WWW). RTT was used to measure the time it takes for a packet to travel from a source across a network to a destination and back. RTT examined the average throughput reachable by GPRS, EDGE, 3G, and HSDPA network for the two operators. The FTP was used to download a single file. Thus, WWW browsing was a popular application of the Internet in the State of Kuwait. User data rates and latency are methods of QoS testing which are to Key Performance Indicator (KPI) measurement.

Latency is one of major KPI in mobile communication. Lower average latency enables delay sensitive services such as video telephony and Voice over IP (VoIP) based applications to obtain a lower quality of service. End-to-end average ping's time or RTT is used widely to be latency (Mohan et al., 2011; Person, 2008; Tapia et al., 2009). The RTT or latency of existing systems is based on laboratory measurements using 32 byte ping (Mohan et al., 2011; Tapia et al., 2009). The 3 GPP specifications define two types of latency, control-plane latency and user-plane (Laner et al., 2012). Whereas controlplane latency is the time required by the call-setup procedure, user-plane latency describes the one-way transmit time of a data packet at the Internet Protocol (IP) layer from the user equipment to the Radio Access Network (RAN) edge-node or vice versa.

Call setup latency determines how quickly the user can start to receive service, while user-plane latency is important since the performance of applications such as web browsing is sensitive to the RTT to the server (Mohan et al., 2011). Furthermore, there are specific KPIs. Under ideal conditions, the RTT should be closed to 90ms for HSDPA/Release'99 DCH, and 70ms for HSDPA/HSUPA. In practice, this RTT will be increased by the transport delay depending on the location. RTT longer than $150 \mathrm{~ms}$ indicates an issue to troubleshoot. LTE technology provides a value of $20 \mathrm{~ms}$ roundtrip time, which is suitable for real-time applications (Fricke et al., 2012). Table 2 lists the KPI in the latency specifications and latency measurements.

\section{LITERATURE REVIEW}

\section{Comparison of 900MHZ and 2100MHz Networks}

Lodhi, Hathi, Gkekas, and Nahi (2008) studied a coverage comparison between UMTS $900 \mathrm{MHz}$ and UMTS2100MHz bands in the island of Jersey. There was a growing demand in deploying $900 \mathrm{MHz}$ bands because a better coverage when compared with $2100 \mathrm{MHz}$, especially in rural and new areas. 
Their findings indicated that the lower bands provide better radio wave propagation, improved indoor coverage, cost efficient electronic devices, and enormous cost savings benefits. In their studies, (a) the Received Signal Code Power (RSCP), (b) received chip energy relative to the total received power spectral density $\left(\mathrm{E}_{\mathrm{c}} / \mathrm{I}\right.$ ), and (c) Signal to Interference Ratio (SIR) had been used as the three key KPIs.

The studies by Lodhi et al. (2008) also revealed that in addition to the capital expenditures (CAPEX) savings in deploying less number of sites, other benefits of UMTS900 were due to the lower carrier band which allows the signal to propagate further than its equivalent at $2100 \mathrm{MHz}$. The required number of sites in UMTS 900 was reduced by $60 \%$ compared to UMTS 2100 technology. This better propagation environment helps in manufacturing cost effective electronic devices thereby reducing cost for transmit power. Lodhi et al. (2008) then made a conclusion remark stating that UMTS900 provided a perfect replacement of GSM in $900 \mathrm{MHz}$ band.

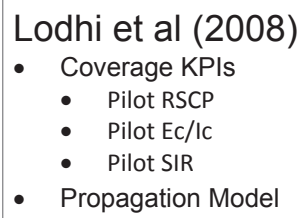

- Radio network dimensioning

- Techno-economic analysis

- CAPEX, OPEX, Revenue Cals

- NPV, Payback, IRR

- Sensitivity Analysis
3G $850 / 900 \mathrm{MHz}$

$3 \mathrm{G} 2100 \mathrm{MHz}$

Figure 1. $900 \mathrm{MHZ}$ and $2100 \mathrm{MHz}$ comparison toward 3G 900MHZ

Furthermore, Simba, Trojer, Mwinyiwiwa, Mvungi, and Mjema (2012) also provided a comparison between UMTS900 and UMTS2100 using a techno-economic analysis to identify the economic feasibility and a costeffective option between these two bands. The cost analysis results indicated that capital and operational costs of UMTS900 technology was lower than UMTS2100. Cost saving on UMTS900 was due to its implementation strategy of re-using the existing GSM network infrastructure. Re-using the existing infrastructure reduced down costs of the civil work, site rental, administration and maintenances. In addition, UMTS900 had a wider coverage compared to the coverage achieved by UMTS2100. 
UMTS900 operated at a lower band, 900MHZ. This had resulted into a longer cell radius compared to a higher frequency technology of $2100 \mathrm{MHz}$. the number of sites for UMTS900 required were less than UMTS2100 to cover the same geographical area. Therefore, fewer sites led to a cost reduction in the CAPEX. Simba et al. (2012) concluded using their techno-economic analysis that to provide a coverage for Tanzania, a connectivity model built from reusing the existing GSM infrastructure to implement $3 \mathrm{G}$ network at $900 \mathrm{MHZ}$ technology was a feasible option and a cost effective preference. Thus, UMTS at $900 \mathrm{MHZ}$ was the better solution in providing broadband access networks for the developing countries, see Figure 1.

\section{Radio Network Optimization}

Radio Network Optimization (RNO) is a complicated process consisting of several phases. The final target for the network optimization is to optimize the network performance. Network optimization contains four processes as shown in Figure 2: KPI definition, network performance monitoring, parameter tuning, and optimized network. Defining KPI is the most important part of the process because it relates to the methodology of optimization (Mishra, 2004). The KPI parameters are responsible directly for the coverage, capacity, and quality of the network. Following this, the network performance monitoring is required to ensure the user satisfaction. Mishra (2004) stated that real time data transfer delay is the critical aspect to be monitored. The quality of a network is viewed from the perspective of users. The parameter tuning includes parameters affecting handover control, packet scheduling, power control, and call admission control. The optimization process is focusing more on performance optimization by configuration changes than on launching. It required the existing network data as an input to the process.

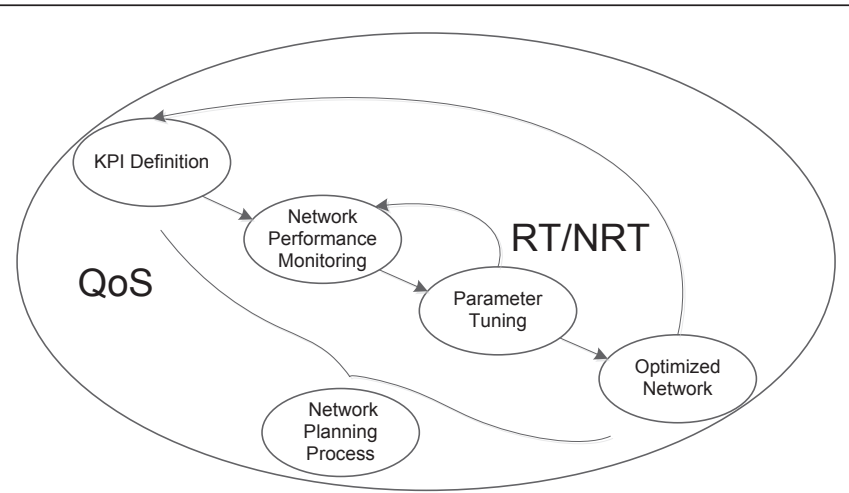

Figure 2. Radio network optimisation by Mishra (2004) 
Moreover, Radio Resource Management (RRM) is responsible for supplying optimum coverage, offering the maximum planned capacity, guaranteeing the required QoS and ensuring efficient use of physical and transport resources. The performance of network can be tuned by finding appropriate parameters settings to achieve a high level of harmony between various functions (Laiho et al., 2006). The network performance tuning is based on the measured data from network elements. Optimization is realized by tuning the configuration parameter settings. Whilst in service, operator needs to react to short term incidents such as traffic load requirements that are different from current network capabilities, network resources need to be reconfigured, and parameters need to be adapted to follow the day-to-day requirements (Laiho et al., 2006).

In addition, Klessig \& Fettweis (2014) presented adaptive admission control which is able to exploit trade-offs between blocking of request and throughput. This was one of the effective network planning and optimization tool set. Finally, Oseni, Popoola, Enumah, \& Gordian (2014) monitored the GSM radio network on $900 \mathrm{MHZ}$ and $1800 \mathrm{MHz}$ by using a drive test based on Transmission Evaluation and Monitoring System (TEMS) in Abeokuta City, Nigeria. The data collected were analyzed in post-processing software tools to identify the causes of problem.

\section{Traffic Engineering}

Effective use of the network resource can optimized the network performance. Thus, a goal of Internet Traffic Engineering (TE) is to use the network resources effectively. Traffic engineering is a task of mapping traffic flows onto an existing physical topology using intelligent routing or/and loadbalancing algorithm for avoiding congested path. This results in providing a better throughput and service quality. Furthermore, traffic classing is a task in the QoS management within UMTS to support translating user's services to an actual physical channel (Laiho et al., 2006).

Recently in Thailand, "TriNet" (a service offered by DTAC) is the network to operate on three different bands: $1800 \mathrm{MHz}, 850 \mathrm{MHz}$, and $2100 \mathrm{MHz}$, enabling the largest possible bandwidth available (Total Access Communication PLC, 2014, "What is TriNet", para. 1). 3G users are being served between $850 \mathrm{MHz}$ and $2100 \mathrm{MHz}$ bands. While $1800 \mathrm{MHz}$ is dedicated for voice calling, $850 \mathrm{MHz}$ provides wide-range coverage. Thus, TriNet is an example of the traffic engineering to utilize the available bands effectively. Added to this, Chimmaee, et al. (2005) proposed an intelligent adaptive load balancer based on hybrid neuro-fuzzy to distribute application traffic between two links. The 
knowledge of application characteristic is needed to train the intelligent load balancer. On the same way, the intelligent radio resource management in the parameter tuning process is acquired knowledge to train in order to tune parameters and map traffic on the physical channel properly.

\section{CONCEPTUAL FRAMEWORKS}

Having laid the groundwork for the development of the conceptual frameworks, this section discusses the proposed performance testing framework and network optimization framework. On the one hand, the network optimization framework consists of KPI definition, network performance monitoring, parameter tuning, and optimized network processes. On the other hand, the performance testing framework deals with the QoS measurements and in particular, the latency, user data rates, and speed tests. As indicated earlier, the network performance monitoring process is needed to support parameter tuning for user's satisfactions. Therefore, an estimation of user experience has been conducted. In this paper, the proposed performance testing framework for operators in Thailand is referred to as "Concept I" (Figure 3). Concept I consists of two obtained knowledge. The first knowledge is for users. The second is knowledge for operators. While the first knowledge is interested by users, the other knowledge is more important for operators. Operators need these information for the network performance monitoring to tune the parameters (Mishra, 2004).

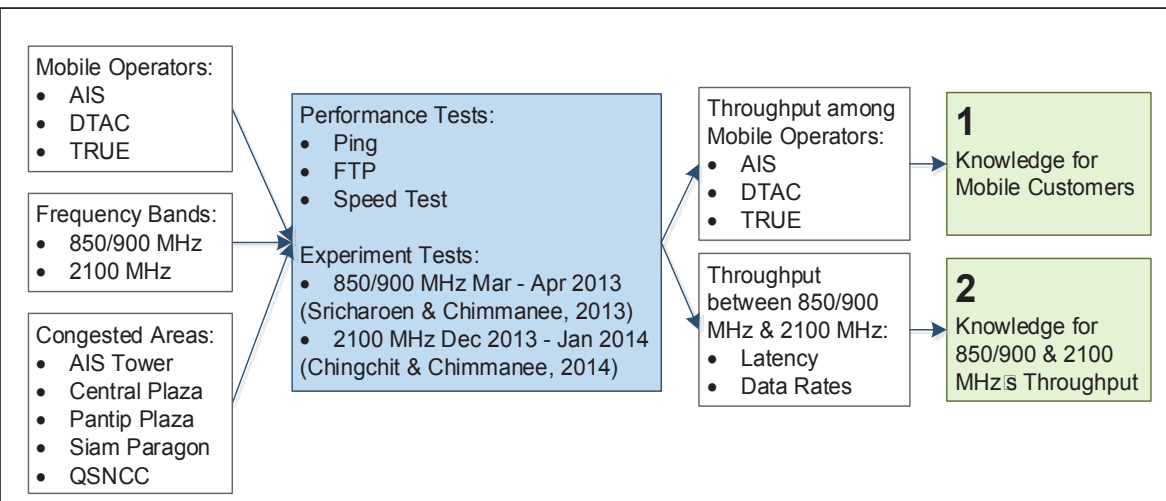

Figure 3. Conceptual framework for performance testing for Thai operators (Concept I) by the Authors

3GPP QoS architecture describes the way network elements participate to support service performance (end-to-end service quality). It is able to 
negotiate service quality support mechanisms and map service performance to the support mechanisms (Laiho et al., 2006). This study focuses on the measurement of the service performance to assist the intelligent support mechanisms. This in turn leads to the proposed conceptual framework of network optimization for operators in Thailand referred to as "Concept II" in Figure 4.

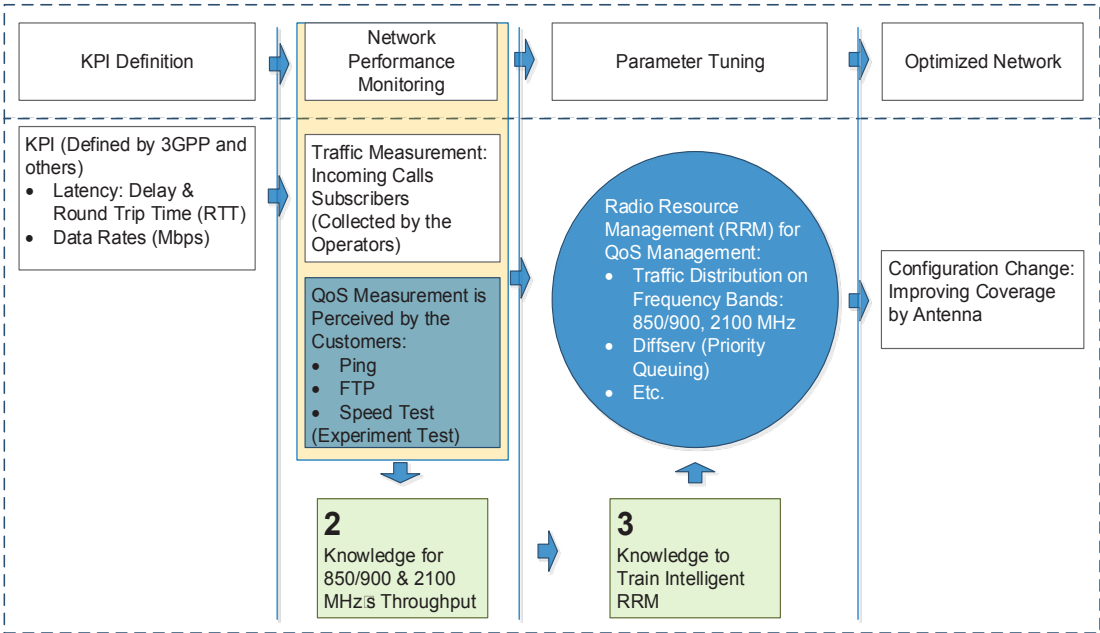

Figure 4. Conceptual framework for network optimization for Thai operators (Concept II) by the authors.

Concept II follows the network optimization process in Mishra (2004) contained four processes. The first process is defined earlier. The third and fourth processes have to be implemented by the operators. Hence, there is only the second process (network performance monitoring) that can be implemented from the user's side, which involves the end-to-end service. It typically requires a certain QoS, which is provided for the user (Laiho et al., 2006). Operator needs to make business decisions depended to the QoS (Laiho et al., 2006). Additionally, this paper presents the implementation of network performance monitoring for operators. The frameworks were develop upon the authors' previous publications. Three publications in particular are of note: (a) "Comparison the efficiency of internet services by $3 G$ technology in Thailand" (Sricharoen \& Chimmanee, 2013); (b) "Performance comparison of internet services using $3 \mathrm{G} 2100 \mathrm{MHz}$ technologies in Bangkok" (Chingchit \& Chimmanee, 2014); (c) "Hybrid neuro-fuzzy based adaptive load balancing for delay-sensitive internet application" (Chimmaee et al., 2005). 
The first process (KPI definition) consists of (1) data rate transfer and (2) latency (RTT). Since Thai operators have been implemented HSPA+ on both $850 / 900 \mathrm{MHz}$ and $2100 \mathrm{MHz}, \mathrm{KPI}$ in the peak data rate in downlink should be about 21 to $28 \mathrm{Mbps}$ as listed in Table 1; and KPI in the latency (RTT) should be during 40 to $50 \mathrm{~ms}$ as listed in Table 2. In the second process (network performance monitoring), there are two major parameters: traffic measurement and QoS measurement. The first measurement includes number of concurrent calls, and number of subscribers, which are provided by the network management system of operators (Laiho et al., 2006). QoS measurement contains two such factors: data rate transfer and latency (RTT) according to KPI definitions in first process. The 3GPP specifications define two types of latency, control-plane latency and user-plane (Mishra, 2004). This paper focuses on the user-plane latency based on the RTT measurements using 32 Byte since the control-plane is responsible for operator's side ping (Person, 2008; Tapia et al., 2009).

The performance testing for the second process as explained in Concept I as shown in Figure 1. The third process (parameter tuning) includes parameters affecting handover control, packet scheduling, call admission control, etc., which involves the Radio Resource Management (RRM) (Laiho et al., 2006). The performance of radio network can be tuned by finding appropriate parameters settings to achieve a high level of harmony between various RRM functions. It has to tune based on measured data from the network performance monitoring process.

Since operators in Thailand have occupied more than one frequencies (850/900MHz and $2100 \mathrm{MHz}$ ), RRM on frequency is therefore one of the QoS attribute mapping in Laiho et al. (2006). The intelligent RRM in the parameter tuning is acquired this knowledge to train in order to tune parameters and map traffic on the physical channel appropriately. Therefore, the knowledge for $850 / 900$ and $2100 \mathrm{MHz}$ throughput that is the outcome of this paper is the important input for the parameter tuning as demonstrated in Figure 4.

\section{METHODOLOGY}

Whereas Figure 3 demonstrates the proposed conceptual framework for performance testing for Thai operators (Concept I), Figure 4 presents the proposed conceptual framework for network optimization for Thai operators (Concept II). Following these figures, Figure 5 illustrates the measurement setup in this research. 

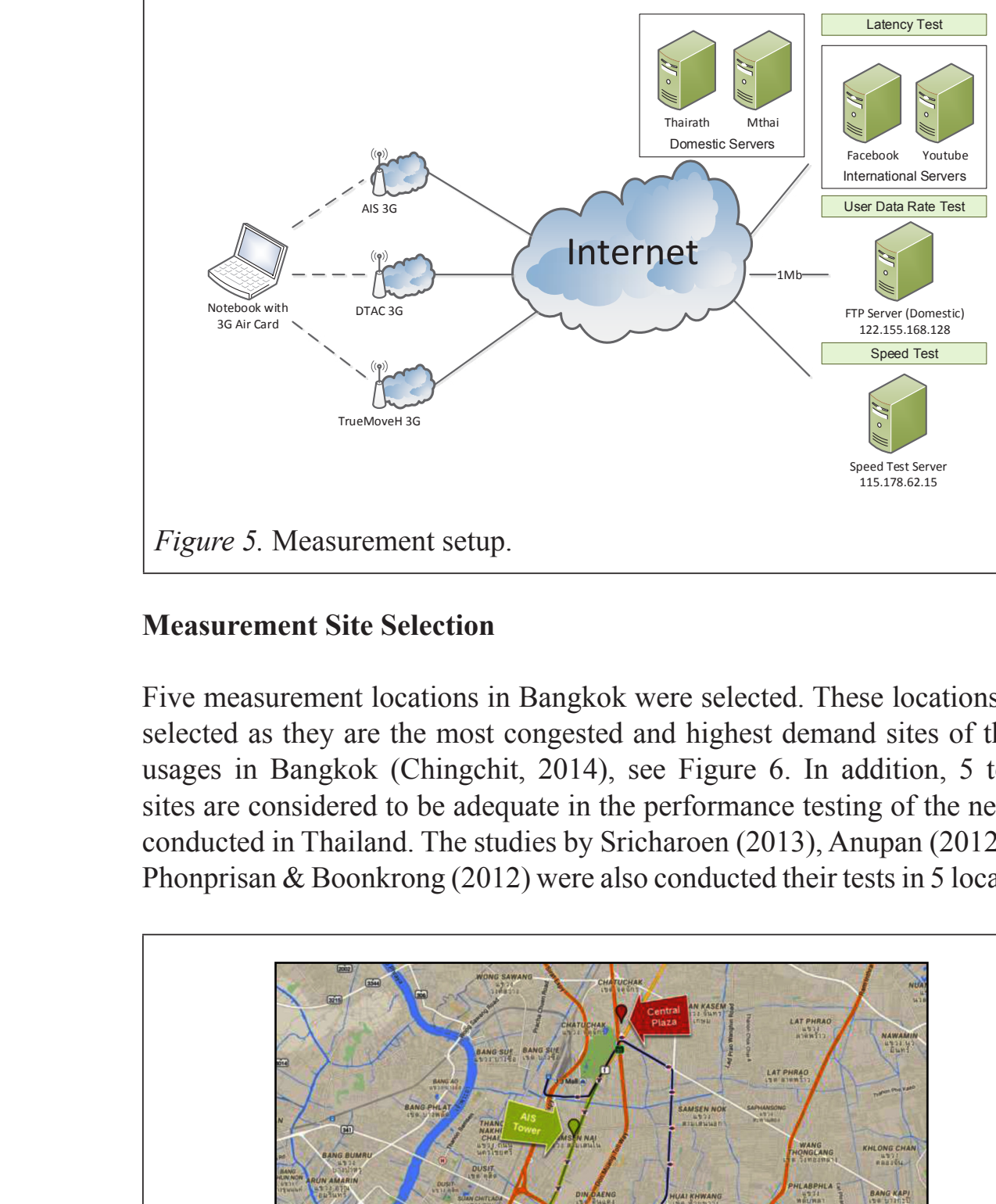

Figure 5. Measurement setup.

\section{Measurement Site Selection}

Five measurement locations in Bangkok were selected. These locations were selected as they are the most congested and highest demand sites of the $3 \mathrm{G}$ usages in Bangkok (Chingchit, 2014), see Figure 6. In addition, 5 testing sites are considered to be adequate in the performance testing of the network conducted in Thailand. The studies by Sricharoen (2013), Anupan (2012), and Phonprisan \& Boonkrong (2012) were also conducted their tests in 5 locations.

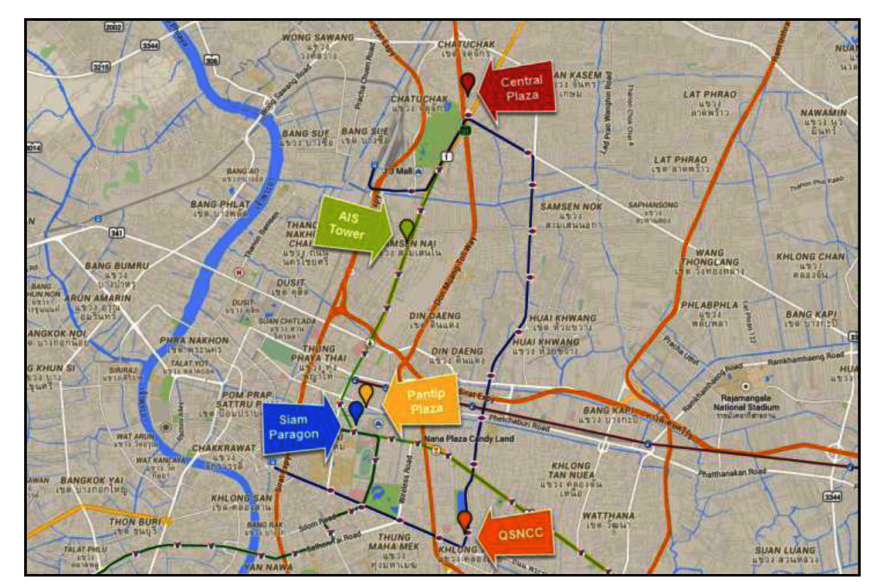

Figure 6. Map of the measurement locations. 
The selected measurement locations are (1) AIS Tower, a company head office on Phaholyothin Road in Phayathai district; (2) Central Plaza Lardprao, an integrated shopping complex on Phaholyothin Road in Chatuchak district; (3) Siam Paragon, a shopping complex and department store on Rama 1 Road in Pathumwan district; (4) Pantip Plaza, an indoor IT shopping mall located on New Phetchaburi Road in Ratchathewi district; and (5) Queen Sirikit National Convention Center (QSNCC), a convention center and exhibition hall located on New Rachadapisek Road in Klongtoey district. Table 3 presents the approximate distance between these locations in kilometers (KM).

Table 3

Distance Chart between the Measurement Locations

\begin{tabular}{lccccc}
\hline & Siam Paragon & Pantip Plaza & QSNCC & AIS Tower & Central Plaza \\
\hline Siam Paragon & & $0.5 \mathrm{KM}$ & $3.8 \mathrm{KM}$ & $4.5 \mathrm{KM}$ & $8.5 \mathrm{KM}$ \\
Pantip Plaza & $0.5 \mathrm{KM}$ & & $3.9 \mathrm{KM}$ & $4.1 \mathrm{KM}$ & $8.2 \mathrm{KM}$ \\
QSNCC & $3.8 \mathrm{KM}$ & $3.9 \mathrm{KM}$ & & $7.4 \mathrm{KM}$ & $10.7 \mathrm{KM}$ \\
AIS Tower & $4.5 \mathrm{KM}$ & $4.1 \mathrm{KM}$ & $7.4 \mathrm{KM}$ & & $3.9 \mathrm{KM}$ \\
Central Plaza & $8.5 \mathrm{KM}$ & $8.2 \mathrm{KM}$ & $10.7 \mathrm{KM}$ & $3.9 \mathrm{KM}$ & \\
\hline
\end{tabular}

\section{Measurement Periods}

The measurement processes were conducted during (1) March to April 2013 (prior to 3G 2100MHz launched in Thailand) and (2) December 2013 to January 2014. The measurements were performed on both weekdays and weekends. The measurements were conducted during morning, afternoon, and evening periods. The morning period was from $8 \mathrm{AM}$ to $12 \mathrm{PM}$. The afternoon period was from 12.01 $\mathrm{PM}$ to $6 \mathrm{PM}$, and 6.01 $\mathrm{PM}$ to $8 \mathrm{PM}$ in the evening period. The measurements were performed at one location each day. The order of these measurements is presented in Table 4. The findings were obtained using means from three measurements in each period.

Table 4

Measurement Periods

\begin{tabular}{cll}
\hline \multicolumn{1}{c}{ Periods } & Times & Operators \\
\hline \multirow{2}{*}{ Morning (8 AM to 12 PM) } & 8 AM - 9.10 AM & AIS \\
& $9.20 \mathrm{AM}-10.30 \mathrm{AM}$ & DTAC \\
& $10.40 \mathrm{AM}-11.50 \mathrm{AM}$ & TrueMoveH \\
\hline & & (continued)
\end{tabular}




\begin{tabular}{lll}
\hline \multicolumn{1}{c}{ Periods } & Times & Operators \\
\hline \multirow{2}{*}{ Afternoon (12 PM to 4 PM) } & $12.01 \mathrm{PM}-1.11 \mathrm{PM}$ & TrueMoveH \\
& $1.21 \mathrm{PM}-2.31 \mathrm{PM}$ & AIS \\
& $2.41 \mathrm{PM}-3.51 \mathrm{PM}$ & DTAC \\
& $4.01 \mathrm{PM}-5.11 \mathrm{PM}$ & DTAC \\
Evening (4 PM to 8 PM) & $5.21 \mathrm{PM}-6.31 \mathrm{PM}$ & TrueMoveH \\
& $6.41 \mathrm{PM}-7.51 \mathrm{PM}$ & AIS \\
\hline
\end{tabular}

\section{Measurement Equipment}

Figure 7 depicts the equipment used in our measurements. Anotebook computer equipped with a 3G/HSDPA data card and 3G Subscriber Identity Module (SIM) cards from three mobile phone operators (AIS, DTAC, and TrueMoveH) for the network connections were used to conduct the measurements.

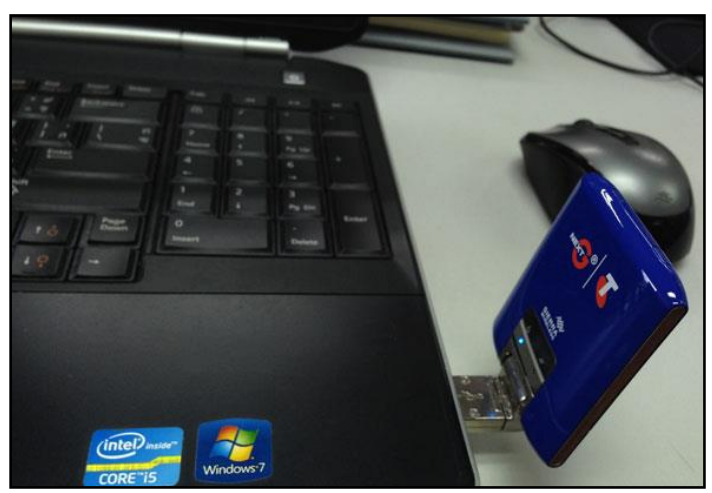

Figure 7. Measurement equipment.

The notebook has an Intel ${ }^{\circledR}$ Core $^{\mathrm{TM}}$ i5-2520 CPU@2.50GHz and 4GB of memory (RAM) running 32-bit Windows 7 Professional Operating System.

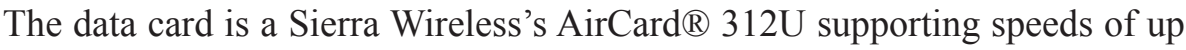
to $42 \mathrm{Mbps}$, see Table 5. Added to this, the following measurement software were used in this study: Ping Utility hrPING v3.6.0.2, Internet Explorer (IE) 10, Microsoft Excel 2007 and Microsoft Access 2007.

\section{Measurement tests}

This study employed three measurement tests covering the Internet services provided by the three $3 \mathrm{G}$ network operators. 
Table 5

Measurement Equipment Details

\begin{tabular}{llll}
\hline \multirow{2}{*}{ Brand / Model } & \multicolumn{2}{c}{$\begin{array}{c}\text { Frequency } \\
\text { Bands }\end{array}$} & \multicolumn{2}{c}{ Technology / Speed } \\
\cline { 3 - 4 } & \multicolumn{1}{c}{ Download } & \multicolumn{1}{c}{ Upload } \\
\hline Sierra Wireless / 312U & $2100 \mathrm{MHz}$ & HSDPA 42Mbps DL & HSUPA 5.76Mbps UL \\
Option / iCON461 & $850 / 900 \mathrm{MHz}$ & *HSUPA 7.2Mbps DL & HSUPA 5.76Mbps UL \\
\hline
\end{tabular}

Table 6

Literature Review on QoS Requirement and Measurement in 3G / 4G

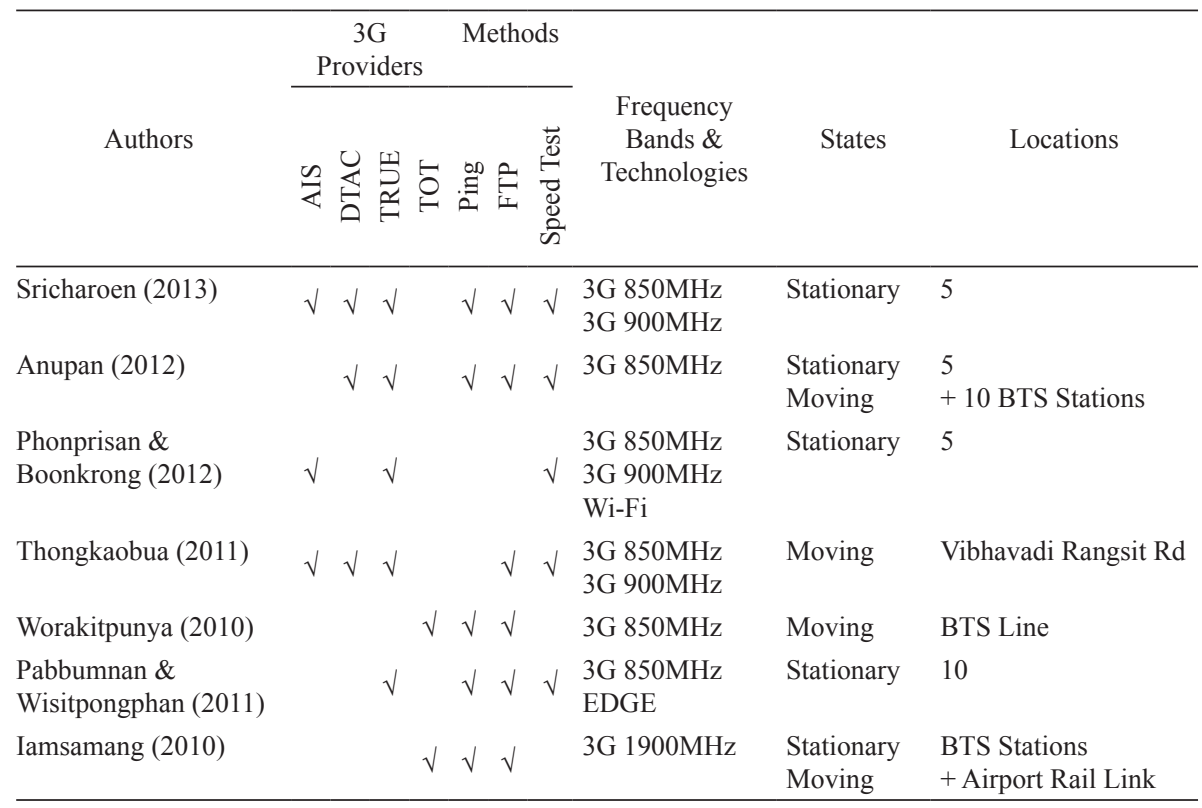

These measurements tests included the latency, user data rates, and speed test measurements. Table 6 presents the mapping between 3G operators, measurement tools, frequency bands, technologies, and measurement sites identified in literature in Thailand.

\section{Latency}

The latency is measured as the Round Trip Time (RTT). By utilizing the Internet Control Message Protocol (ICMP) ping command, it is possible to time the latency. While, there is a Ping utility in Windows OS, hrPing has more features available. For example, the sequence numbers of the replies are 
listed, the times in microseconds ( $\mu$ s) with 3 decimals, the number of bytes in the received packet, the IP identification field, and the standard deviation, see Figure 8. In total, there were four tested websites in conducting the latency measurements. The websites were based on their rank which is calculated using a combination of average visitors and page views over the period. These four websites were obtained from the "top 500 sites on the web" by Alexa Internet Inc (2012, para. 1) and the "top ten websites" by Internet Innovation Research Center Co Ltd (2012, "Truehits Sites", para. 1). They were grouped into domestic and international websites. www.thairath.co.th and www.mthai. com were two of Thailand's domestic's websites. www.facebook.com and www.youtube.com were the international websites.

\begin{tabular}{|c|c|}
\hline C:Iping unw.google.com & C:l>hrping www.google.com \\
\hline Pinging www.google.com [74.125.135.106] with 32 bytes of data: & This is hrPING v3.12 by cFos Software GmbH - http://www.cfos.de \\
\hline \multicolumn{2}{|l|}{ Reply from 74.125.135.106: bytes $=32$ time $=39 \mathrm{~ms} T \mathrm{TT}=49$} \\
\hline Reply from $74.125 .135 .106:$ bytes $=32$ time $=211 \mathrm{~ms} T T L=49$ & Source address is 10.1.228.188; using ICMP echo-request \\
\hline Reply from 74.125 .135 .106 : bytes $=32$ time $=245 \mathrm{~ms} T T=49$ & Pinging www.google.com [173.194.126.84] \\
\hline Reply from 74.125.135.106: bytes=32 time=215ms $T T=49$ & with 32 bytes data ( 60 bytes IP): \\
\hline Ping statistics for 74.125.135.106: & Reply from 173.194.126.84: seq=0001 time $=35.174 \mathrm{~ms} T T L=53 \mathrm{ID}=858 \mathrm{c}$ \\
\hline Packets: Sent $=4$, Received $=4$, Lost $=0$ (0\% loss), & Reply from 173.194.126.84: seq=0002 time=57.328ms $T T L=53 \mathrm{ID}=858 \mathrm{~d}$ \\
\hline Approximate round trip times in milli-seconds: & Reply from 173.194.126.84: seq=0003 time=217.279ms TTL=53 ID=8590 \\
\hline \multirow[t]{4}{*}{ Minimum $=39 \mathrm{~ms}$, Maximum $=245 \mathrm{~ms}$, Average $=177 \mathrm{~ms}$} & Reply from 173.194.126.84: seq=0004 time $=66.806 \mathrm{~ms} T \mathrm{TL}=53 \mathrm{ID}=8592$ \\
\hline & Statistics for www.google.com: \\
\hline & Packets: sent=4, rovd=4, error $=0$, lost $=0$ ( $0.0 \%$ loss $)$ in $1.566799 \mathrm{sec}$ \\
\hline & RTTs of replies in ms: min/avg/max/dev: 35.174 / 94.146 / 217.279 / 72.011 | \\
\hline
\end{tabular}

Figure 8. An example of results from Ping and hrPing commands.

\section{User data rates}

All data rate measurements were performed during off peak and peak hours in order to monitor the realistic usages of the networks. In all locations, download (DL) and upload (UL) file transfers are performed. The file transfers are performed via the file transfer protocol (FTP), and the average FTP DL or UL throughput is computed per file transfer. FTP test with FileZilla software testing was performed to transfer $1 \mathrm{MB}$ file by downloading, uploading, and collecting the data. Measurements are in a unit of seconds (s).

\section{Speed test}

The speed test measures the network download and upload speed. The measurement performs three measurements, download speed, upload 
speed and round trip time (RTT) resulting in kbps and ms respectively. The measurements begin by entering http://speedtest.adslthailand.com/ into the URL.

\section{RESULTS}

This section presents the measurement results base on the measurement tests from a qualitative and quantitative perspective.

\section{Latency Measurement Results}

Figures 9 and 10 display the outcome of the latency measurements. The findings indicated that AIS was leading the rest of the operators on the average RTT values when tested with the domestic websites. For the international websites, TrueMoveH was the best performance overall. Thus, the latency measurement results on $3 \mathrm{G} 2100 \mathrm{MHz}$ were clearly better than on $3 \mathrm{G} 850 / 900 \mathrm{MHz}$.

Figure 9 displays the bar charts of the ping's average results to "www.thairath. co.th" and "www.mthai.com" in milliseconds (ms). The findings indicated that when pinged to "www.thairath.co.th", AIS had obtained the best results 3 out of the 5 locations, followed by TrueMoveH, and DTAC. Similarly, AIS had obtained the best results 3 out of the 5 locations when pinged to "www.mthai. com". Hence, AIS Tower had the fastest RTT average in both measurements.

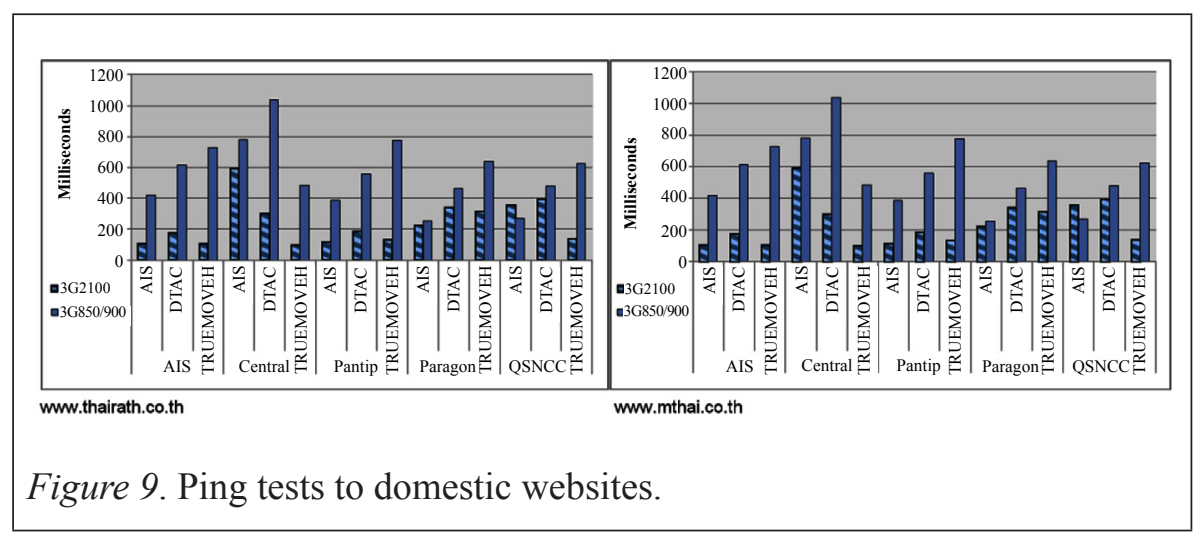

Figure 10 displays the bar charts of the ping's average results to "www. facebook.com" and "www.youtube.com" in milliseconds. The findings indicated that when pinged to "www.facebook.com" and "www.youtube.com", AIS had obtained the best ping's results 3 out of the 5 locations, followed by TrueMoveH (2 out of 5), and DTAC. Despite this result, TrueMoveH had the 
best results in terms of RTT's average. Similar to the domestic websites, AIS Tower had the fastest RTT average in both measurements.

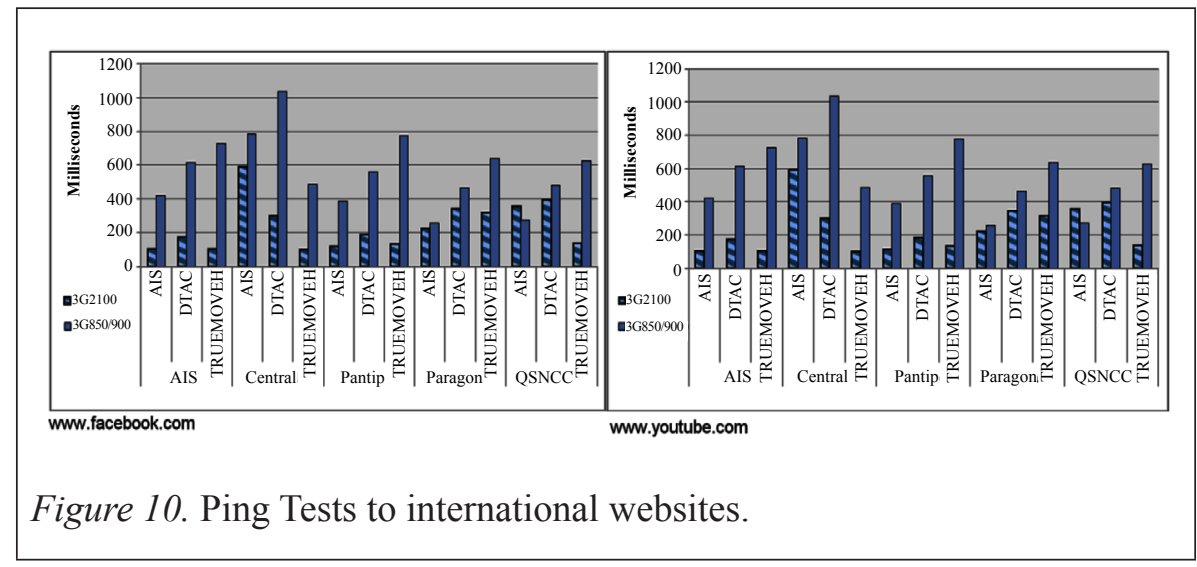

\section{User Data Rates Measurement Results}

A number of measurements were performed to examine the average user data rate reachable by the $3 \mathrm{G}$ networks on $2100 \mathrm{MHz}$ and $850 / 900 \mathrm{MHz}$ provided by the three operators in Thailand. FileZilla was used to measure both download and upload speed of a file size $1 \mathrm{MB}$. Figure 11 presents the download and upload speed in seconds.

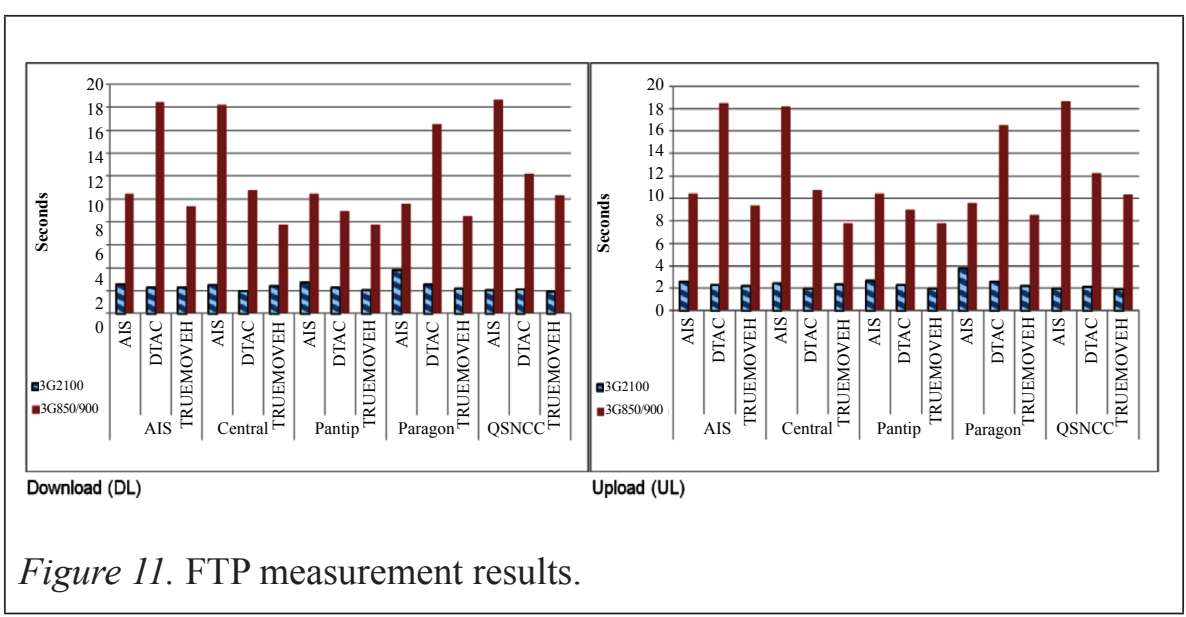

The results as shown in Figure 11 demonstrate that TrueMoveH had the best average download and upload speed when downloading and uploading 1MB file in size, followed by DTAC, and AIS respectively. It is also appropriate to note that that the lowest bar height means the best performance. 


\section{Speed Test Measurement Results}

The speed test measurement via "http://speedtest.adslthailand.com" was used to obtain the average speed in kbps. Figure 12 demonstrates that DTAC was the best performance on the average speed test measurements when downloading, followed by TrueMoveH, and AIS respectively. In contrast, TrueMoveH gave the best performance in terms of uploading; while DTAC was the next, then AIS.

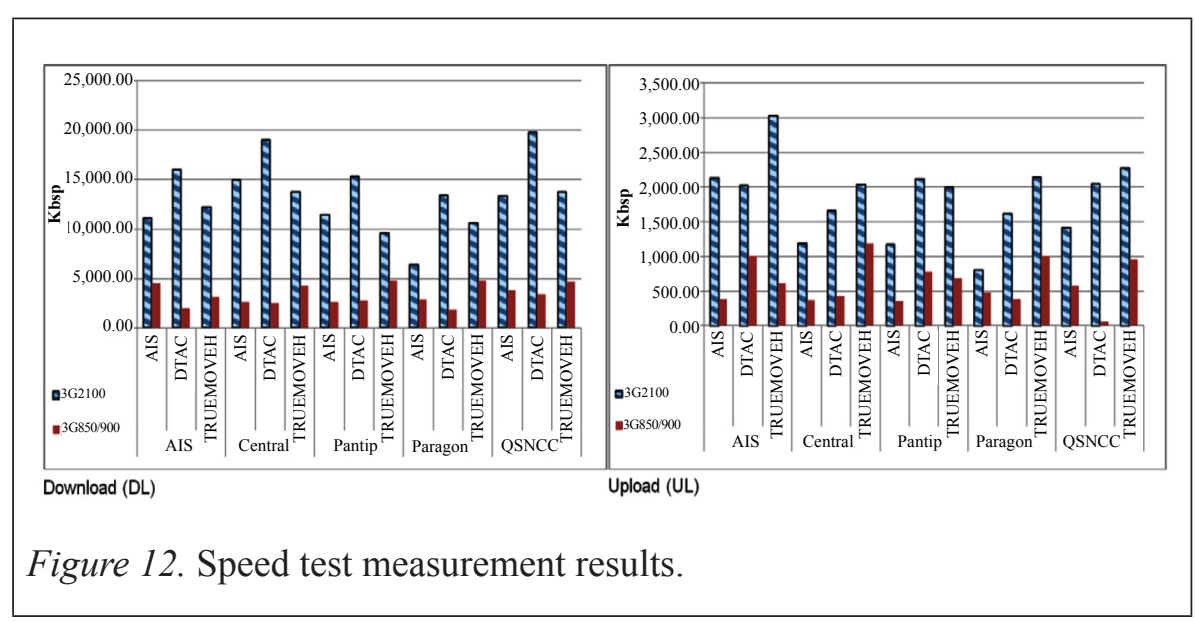

\section{DISCUSSION}

Table 7 presents the overall average measurement findings. The findings clearly indicated the better performance in terms of the latency, user data rates, and speed test measurements from $3 \mathrm{G}$ on $2100 \mathrm{MHz}$ over $850 / 900 \mathrm{MHz}$ bands. The best performances in each measurement are highlighted and presented in each of the following Tables. Accordingly, these operators were able to provide the maximum bandwidth of $42 \mathrm{Mbps}$ in both $2100 \mathrm{MHz}$ and $850 / 900 \mathrm{MHz}$ bands. This is clearly exceeded the standard $3 \mathrm{G}$ transmission speed of $2.05 \mathrm{Mbps}$ and $3 \mathrm{Mbps}$ as reported in the studies by Garber (2002) and Hartung et al (2007). Two anticipate reasons are as follows. The first reason is that while these measurements were conducted at the same locations, dates and time periods for testing were different. The second reason was that the $3 \mathrm{G}$ on $850 / 900 \mathrm{MHz}$ are being shared between $2 \mathrm{G}$ and $3 \mathrm{G}$ usages.

The performance of the network providers on $850 / 900 \mathrm{MHz}$ are listed in Table 8. According to the measurement test findings, AIS performed best in the latency measurements. TrueMoveH was out performed in the user data 
rates, and speed test measurements. DTAC was at a moderate level in each measurement. All of the providers had met the standard set by the NBTC report (NBTC, 2014). The standard states that (1) the RTT must not be over 500 milliseconds; (2) the bandwidth for downloading must not be lower than $345 \mathrm{kbps}$; and (3) the bandwidth for uploading must not be lower than $153 \mathrm{kbps}$.

Table 7

Average Values of $3 \mathrm{G}$ on $2100 \mathrm{MHz}$ and $850 / 900 \mathrm{MHz}$ Measurements

\begin{tabular}{lccccc}
\hline \multirow{2}{*}{ Frequency Bands } & Ping (Millisecond) & \multicolumn{2}{c}{ Speed Test (kbps) } & \multicolumn{2}{c}{ FTP (Seconds) } \\
\cline { 2 - 6 } & & Download & Upload & Download & Upload \\
\hline 3G $2100 \mathrm{MHz}$ & 247.43 & 13394.25 & 1842.71 & 2.35 & 7.71 \\
$3 \mathrm{G} 850 / 900 \mathrm{MHz}$ & 525.56 & 3362.14 & 614.62 & 11.85 & 5.90 \\
\hline
\end{tabular}

Table 8

Average Values of $3 G$ on 850/900MHz Measurements by Providers and NCBT Standard

\begin{tabular}{lcccccc}
\hline 3G 850/900MHz & $\begin{array}{c}\text { Ping } \\
\text { Domestic }\end{array}$ & $\begin{array}{c}\text { Ping } \\
\text { International }\end{array}$ & \multicolumn{2}{c}{ Speed Test (kbps) } & \multicolumn{2}{c}{ FTP (Seconds) } \\
\cline { 5 - 8 } & (Milliseconds) & (Millisecond) & Download & Upload & Download & Upload \\
\hline AIS & 410.82 & 399.37 & 3271.21 & 429.52 & 13.46 & 69.68 \\
DTAC & 542.61 & 677.77 & 2515.44 & 530.56 & 13.37 & 73.13 \\
TrueMoveH & 465.73 & 657.04 & 4299.78 & 883.77 & 8.73 & 27.89 \\
NCBT Standard & 500 & 500 & 345 & 153 & - & - \\
\hline
\end{tabular}

The measurement test results as shown in Table 9 indicated that TrueMoveH on the $3 \mathrm{G} 2100 \mathrm{MHz}$ was the best performance in all measurements except from the downloading in the speed test. While, DTAC was the best in this speed test measurement under downloading, other measurements were only at the moderate level.

In terms of $2100 \mathrm{MHz}$ and $850 / 900 \mathrm{MHz}$ band, see Table 10 . Whereas, TrueMoveH offered the best performance in the user data rates measurement; AIS was the best in the latency measurement to both domestic and international websites. The speed test measurement was spitted between DTAC and TrueMoveH. The report by NBTC (2014) indicated that DTAC had the best performance in the user data rates during November 2013 to February 
2014. Therefore, our findings were resulted in accordance with the NBTC report. It is also appropriate to note that our user data rates measurement was also measured in seconds. Hence, the throughput performance in kbps was considered to be valid under the speed test measurement.

Table 9

Average Values of $3 \mathrm{G}$ on $2100 \mathrm{MHz}$ Measurements by Providers

\begin{tabular}{lcccccc}
\hline 3G 2100MHz & $\begin{array}{c}\text { Ping } \\
\text { Domestic }\end{array}$ & $\begin{array}{c}\text { Ping } \\
\text { International }\end{array}$ & \multicolumn{2}{c}{ Speed Test (kbps) } & \multicolumn{2}{c}{ FTP (Seconds) } \\
\cline { 5 - 8 } & (Milliseconds) & (Millisecond) & Download & Upload & Download & Upload \\
\hline AIS & 179.25 & 283.41 & 11473.34 & 1339.86 & 2.69 & 9.21 \\
DTAC & 357.90 & 310.09 & 16713.37 & 1892.72 & 2.23 & 8.16 \\
TrueMoveH & 174.56 & 179.12 & 11996.04 & 2295.56 & 2.13 & 5.77 \\
\hline
\end{tabular}

Table 10

Average Values of $3 \mathrm{G}$ on $850 / 900 \mathrm{MHz}$ and $2100 \mathrm{MHz}$ Measurements by Providers

\begin{tabular}{|c|c|c|c|c|c|c|}
\hline \multirow{2}{*}{$\begin{array}{c}3 \mathrm{G} 850 / 900 \mathrm{MHz} \\
\& \\
3 \mathrm{G} 2100 \mathrm{MHz}\end{array}$} & \multirow{2}{*}{$\begin{array}{c}\text { Ping } \\
\text { Domestic } \\
\text { (Milliseconds) }\end{array}$} & \multirow{2}{*}{$\begin{array}{c}\text { Ping } \\
\text { International } \\
\text { (Millisecond) }\end{array}$} & \multicolumn{2}{|c|}{ Speed Test (kbps) } & \multicolumn{2}{|c|}{ FTP (Seconds) } \\
\hline & & & Download & Upload & Download & Upload \\
\hline AIS & & & & & & \\
\hline DTAC & & & & & 7.80 & \\
\hline TrueMoveH & 320.15 & 418.08 & 8147.91 & 1589.66 & 5.43 & 16.83 \\
\hline
\end{tabular}

\section{Knowledge factors}

The comparison of $900 \mathrm{MHZ}$ and $2100 \mathrm{MHz}$ (Figure 1) suggested that $850 / 900 \mathrm{MHz}$ was more preferred than $2100 \mathrm{MHz}$ for $3 \mathrm{G}$ implement. In contrast to this comparison, this paper presents that $2100 \mathrm{MHz}$ is more suitable for supporting high data rate respect to user satisfaction and leads toward $4 \mathrm{G}$. Our research findings has confirmed the objectives that there is a need to acquire knowledge from the QoS measurement within the network performance monitoring process. These knowledge then feed into the train or usage in the parameter tuning process according to Concept II. The major knowledge factors and diagram for training the intelligent Radio Resource Management (RRM) in the parameter tuning for such traffic engineering between $850 / 900 \mathrm{MHz}$ and $2100 \mathrm{MHz}$ bands are presented in Figure 13. 


\section{Knowledge Factor 1}

The results and findings in the "Comparison of $900 \mathrm{MHZ}$ and $2100 \mathrm{MHz}$ networks" section indicated that while $850 / 900 \mathrm{MHz}$ frequencies have larger coverage areas, these frequencies are not suitable for high or dense data usages. Instead, high frequencies such as $2100 \mathrm{MHz}$ have a lower coverage areas but can process larger quantities of data at a higher speed. Thus, the nature of these frequencies is also different.

\section{Knowledge Factor 2}

Traffic measurements: number of concurrent calls, number of subscribers (collected by operators) as shown in Concept II (Figure 4).

\section{Knowledge Factor 3}

QoS measurements: average data rate, average latency (monitored by user's side) as shown in Concept II (Figure 4). Although operators already have the information of the traffic measurement factors such as numbers of concurrent calls and/or subscribers; the operators need information from the QoS measurement factors for integrating these factors to train the intelligent RRM, i.e., load balancer, scheduling policies that a class with higher priority is always processed first compared with a lower priority (Ghazali \& Harun, 2012).

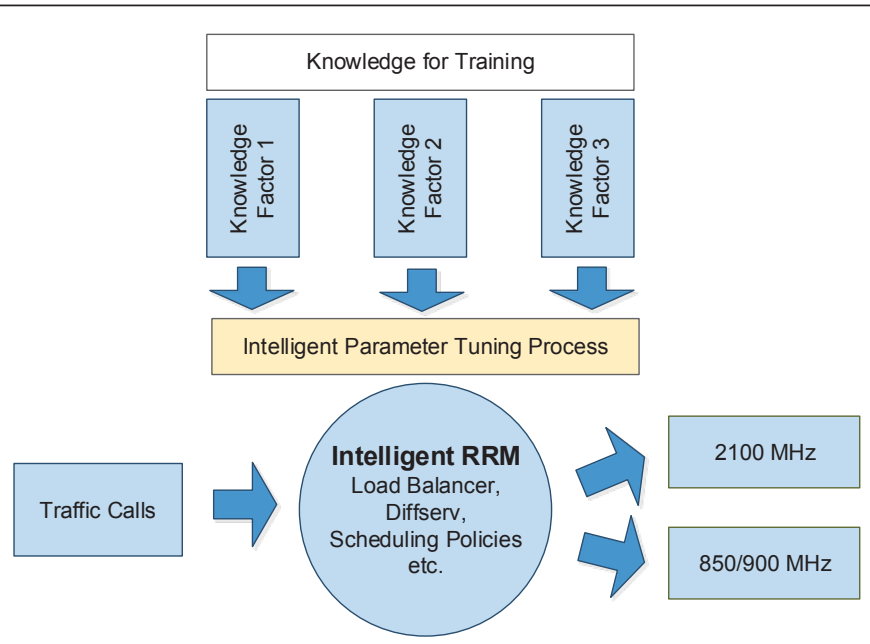

Figure 13. Applying the acquired knowledge from the network performance monitoring process in QoS to train/usage in the parameter tuning process according to concept II. 


\section{Application of Knowledge Factors}

Thus, there are several ways for applying these knowledge. Chimmaee et al. (2005) presented an intelligent load balancer based on hybrid neuro-fuzzy for distributing incoming application traffic between two links. Chimmanee et al. (2005) analogized two links as two classes, and taken a concept of traffic classification for distributing traffic. Before such intelligent load balancer can work properly, knowledge of application characteristic is needed. Examples of this knowledge are volume traffic, packet size, and delay-sensitive, to train the intelligent load balancer. In the same direction, two frequencies are analogized as two classes, which correspond to the traffic classification function in the QoS attribute mapping task of the network optimization process (Laiho et al., 2006). The proposed idea in Figure 13 which is a part of the Concept II framework are to combine the major factors into account in order to support mapping the service performance to the support mechanisms following the 3GPP QoS architecture. Intelligent traffic engineering such as load balancer with the proposed knowledge should be applied to Thai operators.

\section{CONCLUSION}

This study proposed the conceptual frameworks for performance testing and network optimization. It reported the performance comparison of operators conducted in Bangkok according to the Concept I framework in assisting users' satisfaction decision about the services. The performance of $3 \mathrm{G}$ on $850 / 900 \mathrm{MHz}$ on and $2100 \mathrm{MHz}$ frequencies had been evaluated. The test results indicated that $2100 \mathrm{MHz}$ offered the better overall performance than $850 / 900 \mathrm{MHz}$. The latency measurements indicated $47 \%$ better performance than $850 / 900 \mathrm{MHz}$. The user data rate measurements indicated $621 \%$ better performance than $850 / 900 \mathrm{MHz}$. The speed test measurements resulted in $349 \%$ better than its counterpart. In terms of the operators, TrueMoveH offered the best performance in the user data rate measurements; while AIS was the best in the latency measurements to both domestic and international websites. The speed test measurements were spitted between DTAC and TrueMoveH. Moreover, there is a need to obtain the knowledge from the QoS measurements from both $850 / 900 \mathrm{MHz}$ and $2100 \mathrm{MHz}$ because Thai operators already occupied both of the frequencies. While Thai operators may have information about their traffic measurements, the QoS which is perceived by the users are needed. Finally, this study had not only proffered the conceptual frameworks but has also presented evidence that supports the propositions, which the operators in Thailand could take information of the acquired knowledge into their account for Intelligent RRM in the parameter tuning. 


\section{ACKNOWLEDGEMENTS}

The authors express the most sincere thanks to Sitthipun Chingchit, Phitsanuluk

Sricharoen, and Sittisak Kantala for their contributions.

\section{REFERENCES}

3GPP. (2014). GPRS \& EDGE. Retrieved from http://www.3gpp.org/ technologies/ keywords-acronyms/102-gprs-edge

Abdullah, M. F. L., Abdullah, J., Yonis, A. Z., \& Ghanim, M. F. (2011). Comparison study on $3.9 \mathrm{G}$ and $4 \mathrm{G}$ evolution. Proceedings of the 2011 International Conference on Information Communication and Management (pp. 181-186). Singapore.

Alexa Internet Inc. (2012). The top 500 sites on the web. Retrieved from $\mathrm{http} / / / \mathrm{www} \cdot$ alexa .com/topsites

Almutairi, A. F., Al-Jame, F., \& A-Buraikan, A. (2009). GPRS/EDGE/3G/ HSDPA networks performance measurements in the State of Kuwait. Proceedings of the 5th IEEE GCC Conference \& Exhibition (pp. 1-3). Kuwait City, Kuwait.

Anupan, I. (2012). The measurement and comparison of $3 G$ performance via mobile phone between True Move H and Dtac. (Unpublished master's thesis). King Mongkut's of University Technology North Bangkok, Thailand.

Cela, S., Kamo, B., Cakaj, S., Muka, Q., \& Mitrushi, R. M. (2013). An algorithm for processing the measurement results of electromagnetic field near $2 \mathrm{G}$ and $3 \mathrm{G}$ base stations in Albanian territory. Proceedings of the 21st IEEE International Conference on Software, Telecommunications and Computer Networks (SoftCOM) (pp. 1-5). Primosten, Croatia.

Chen, Y., Towsley, D., Nahum, E. M., Gibbens, R. J., \& Lim, Y. (2012). Characterizing $4 \mathrm{G}$ and $3 \mathrm{G}$ networks: supporting mobility with multipath TCP. UMass Amherst Technical Report, 22, 1-13.

Chimmaee, S., Wupusitwarakun, K., \& Runggeratigul, S. (2005). Hybrid neuro-fuzzy based adaptive load balancing for delay-sensitive internet application. Journal of Intelligent and Fuzzy System (JIFS), 16(2), 79-93. 
Chingchit, S. (2014). Performance comparison of Internet services using $3 G$ $2100 \mathrm{MHz}$ technologies in Bangkok. (Unpublished master's thesis). Rangsit University, Thailand.

Chingchit, S., \& Chimmanee, S. (2014). Performance comparison of internet services using 3G $2100 \mathrm{MHz}$ technologies in Bangkok. Proceedings of the SAU National Interdisciplinary Conference (pp. 20-29). Bangkok, Thailand.

Darst, C., \& Ramanathan, S. (1999). Measurement and management of internet services. Proceedings of the 6th IFIP/IEEE International Symposium on Integrated Network Management and Distributed Management for the Networked Millennium (pp. 125-140). Boston, United States.

ETDA. (2013). Thailand Internet user profile 2013. Bangkok, Thailand: Author.

ETSI. (2014a). EDGE. Retrieved from http://www.etsi.org/index.php/ technologies-clusters/technologies/mobile/edge

ETSI. (2014b). General packet radio service, GPRS. Retrieved from http:// www.etsi.org/ technologies-clusters/technologies/mobile/gprs?highlig ht=YToxOntpOjA7czo0OiJncHJzIjt9

Fricke, M., Heckwolf, A., Herber, R., Nitsch, R., Schwarze, S., \& Voß, S. (2012). Requirements of 4G-based mobile broadband on future transport networks. Journal of Telecommunications and Information Technology, 2, 21-28.

Garber, L. (2002). Will 3G really be the next big wireless technology. Computer, 35(1), 26-32.

Ghazali, O., \& Harun, N. Z. (2012). Implementation and validation of an adaptive FEC machanism for video transmission. Journal of Information and Communication Technology, 11, 55-74.

Hartung, F., Horn, U., Huschke, J., Kampmann, M., Lohmar, T., \& Lundevall, M. (2007). Delivery of broadcast services in $3 \mathrm{G}$ networks. IEEE Transactions on Broadcasting, 53(1), 188-199.

Haryadi, S., \& Andina, R. (2012). QoS measurement of file transfer protocol services in $3 \mathrm{G}$ networks using aggregation method. Proceedings of the 
7th IEEE International Conference on Telecommunication Systems, Services, and Applications (TSSA) (pp. 107-110). Bali, Indonesia.

Hu, Y., Liu, J., \& Tan, X. (2010). Digital modulation recognition based on instantaneous information. The Journal of China Universities of Posts and Telecommunications, 17(3), 52-90.

Iamsamang, W. (2010). Performance analysis of $3 G$ data service on the underground mass rapid transit authority of Thailand (MRTA) Bangkok airport train and department store and shopping mall. (Unpublished master's thesis). King Mongkut's of University Technology North Bangkok, Thailand.

Internet Innovation Research Center Co Ltd. (2012). Top 10 websites. Retrieved from http://truehits.net

Jørgensen, N. T., Rodriguez Larrad, I., Elling, J., \& Mogensen, P. (2014). 3G Femto or $802.11 \mathrm{~g} \mathrm{WiFi}$ : Which is the best indoor data solution today? Proceedings of the 2014 IEEE Vehicular Technology Conference (VTC Fall) (pp. 1-5). Vancouver, Canada.

Klessig, H., \& Fettweis, G. (2014). Adaptive admission control in interferencecoupled wireless data networks: A planning and optimization tool set. Proceedings of the 2014 IEEE International Conference on Communications (ICC) (pp. 2375-2380). Sydney, Australia.

Kurose, J. F., \& Ross, K. W. (2013). Computer networking: a top-down approach. Upper Saddle River, NJ: Addison-Wesley.

Lachowski, J., Maternia, M., \& Gorzynski, J. (2011). Multiband and multicarrier operations in HSDPA. Proceedings of the 8th International Symposium on Wireless Communication Systems (ISWCS), (pp. 725729). Aachen, Germany.

Laiho, J., Wacker, A., \& Novosad, T. (2006). Radio network planning and optimisation for UMTS. New York, NY: John Wiley \& Sons.

Laner, M., Svoboda, P., Romirer-Maierhofer, P., Nikaein, N., Ricciato, F., \& Rupp, M. (2012). A comparison between one-way delays in operating HSPA and LTE networks. Proceedings of the 10th International Symposium on Modeling and Optimization in Mobile, Ad Hoc and Wireless Networks (WiOpt) (pp. 286-292). Paderborn, Germany. 
Lodhi, A., Hathi, N., Gkekas, Y., \& Nahi, P. (2008). Coverage comparison of UMTS networks in 900 and $2100 \mathrm{MHz}$ frequency bands. Paper presented at the IET International Conference on Wireless, Mobile and Multimedia Networks (pp. 22-25). Beijing, China.

Malisuwan, S., Kaewphanuekrungsi, W., Madan, N., \& Sivaraks, J. (2015). Analysis of $2.1 \mathrm{GHz}$ spectrum auction in Thailand. Journal of Economics, Business and Management, 3(6), 591-598.

Malisuwan, S., Teppayayon, O., Madan, N., Sivaraks, J., \& Kaewphanuekrungsi, W. (2013). Analysis of mobile spectrum management in Thailand to move towards a knowledge based economy: A regulatory review. Journal of Advanced Management Science, 1(3), 288-298.

Mishra, A. R. (2004). Fundamentals of cellular network planning and optimisation: $2 G / 2.5 G / 3 G \ldots$ evolution to $4 G$ : Hoboken, NJ: John Wiley \& Sons.

Mohan, S., Kapoor, R., \& Mohanty, B. (2011). Latency in HSPA data networks. Retrieved from https:/www.qualcomm.com/media/documents/files/ qualcomm-research-latency-in-hspa-data-networks.pdf

Nakamura, T. (2011). 3GPP radio access networks LTE-advanced status. Retrieved from ftp://www.3gpp.org/Information/presentations/present ations_2011/2011_09_LTE_Asia/2011_LTEAsia_3GPP\%20RAN.pdf

NBTC. (2013). Telecommunications consumption survey of Thailand 20122013. Bangkok, Thailand: Author.

NBTC. (2014a). Annual Report on the Operation of the NBTC 2013. Bangkok, Thailand: Author.

NBTC. (2014b). Telecommunication report on $2.1 \mathrm{GHz}$ working group. Bangkok, Thailand: Author.

Oseni, O. F., Popoola, S. I., Enumah, H., \& Gordian, A. (2014). Radio frequency optimization of mobile networks in Abeokuta, Nigeria for improved quality of service. International Journal of Research in Engineering and Technology, 3(8), 174-180.

Pabbumnan, N., \& Wisitpongphan, N. (2011). Performance comparison of accessing Internet mobile phone using EDGE and $3 \mathrm{G}$ technologies. 
Proceedings of the 7th National Conference on Computing and Information Technology (NCCIT2011) (pp. 613-618). Bangkok, Thailand.

Person, J. (2008). Mobile Broadband Comparison. Proceedings of the $3 G$ CDMA Africa and Middle East Regional Conference (pp. 1-12). Cape Town, South Africa.

Phonprisan, G., \& Boonkrong, S. (2012). Analysis and efficiency validation of video file on 3G and Wi-Fi hotspot technology : A case study of video on-demandstreaming. Proceedings of the 8th National Conference on Computing and Information Technology (NCCIT2012) (pp. 853-859). Chonburi, Thailand.

Ramli, R., Jamaluddin, F., Bakar, E. M. N. E. A., Alias, M. Y., Mahat, N. I., \& Karim, M. Z. A. (2013). Assignment of spectrum demands by merits via analytic hierarchy process and integer programing. Journal of Information and Communication Technology, 12, 39-53.

Ranta, P. (2004). Top $103 \mathrm{G}$ optimisation actions. Retrieved January from the Academia website: https://www. academia.edu/7872546/TOP_10_3G_ RAN_Optimisation_Actions_Version_0.4

Real Wireless Ltd. (2012). Timing of consumer and operator features available from HSPA and LTE. Pulborough: England: Author.

Saxena, T., \& Jadon, J. S. (2013). Review on 2G, 3G and 4G radio network planning. International Journal of Engineering, Business and Enterprise Applications, 84-89.

Simba, F., Trojer, L., Mwinyiwiwa, B., Mvungi, N., \& Mjema, E. (2012). Techno-economic analysis of UMTS900 and UMTS2100 for rural connectivity in Tanzania. Proceedings of the 14th IEEE International Conference on Communication Technology (ICCT) (pp. 10-15). Chengdu, China.

Sköld, J., Lundevall, M., Parkvall, S., \& Sundelin, M. (2005). Broadband data performance of third-generation mobile systems. Ericsson Review, 82(1), 14-23.

Sricharoen, P. (2013). Performance comparison of internet services by $3 G$ technology based on 850 and $900 \mathrm{mhz}$ in the most congestion areas in Bangkok (Unpublished master's thesis). King Mongkut's of University Technology North Bangkok, Thailand. 
Sricharoen, P., \& Chimmanee, S. (2013). Comparison the efficiency of internet services by $3 \mathrm{G}$ technology in Thailand. RMUTP Reserach Journal (Special Issue), 20-29.

Tapia, P., Liu, J., Karimli, Y., \& Feuerstein, M. (2009). HSPA performance and evolution: a practical perspective. Bognor Regis, West Sussex: John Wiley \& Sons.

Tarun, M. (2014). 3G KPI Guidelines. Retrieved from https://www.academia. edu/4306825/3G_KPI_guidelines

Thongkaobua, M. (2011). Impact of velocity on $3 G$ network performance. (Unpublished master's thesis). King Mongkut's of University Technology North Bangkok, Thailand.

Total Access Communication PLC. (2014). TriNet 3 smart networks. Retrieved from http://www.dtac.co.th/en/business/trinet/trinet.html

Vacirca, F., Ricciato, F., \& Pilz, R. (2005). Large-scale RTT measurements from an operational UMTS/GPRS network. Proceedings of the 1 st International Conference on Wireless Internet, WICON 2005 (pp. 1-8). Budapest, Hungary.

Worakitpunya, K. (2010). Performance analysis of $3 G$ data service on the Bangkok mass transit system (BTS). (Unpublished master's thesis). King Mongkut's of University Technology North Bangkok, Thailand. 